\title{
Sensitisation for cisplatin-induced apoptosis by isothiocyanate E-4IB leads to signalling pathways alterations
}

\author{
J Bodo', L Hunakova', P Kvasnicka ${ }^{2}$, Jakubikova', J Duraj', J Kasparkova ${ }^{3}$ and J Sedlak*,I \\ 'Laboratory of Tumour Immunology, Cancer Research Institute, Slovak Academy of Sciences, Vlarska 7, Bratislava 833 91, Slovakia; ${ }^{2}$ Department of \\ Nuclear Physics and Biophysics, Faculty of Mathematics, Physics and Informatics, Comenius University, Mlynska dolina FI, Bratislava 842 15, Slovakia; \\ ${ }^{3}$ Institute of Biophysics, Academy of Sciences of the Czech Republic, Kralovopolska 135, Brno CZ-61265, Czech Republic
}

A new synthetic isothiocyanate (ITC) derivative, ethyl 4-isothiocyanatobutanoate (E-4IB), appeared to be an effective modulator of cellular proliferation and potent inducer of apoptosis. In cooperation with cisplatin, this compound exerted synergistic effects in human ovarian carcinoma A2780 cells. In the present study we investigated in more detail E4IB-sensitisation for cisplatin-induced apoptosis. Sequential administration of both cytostatic agents led to increased intracellular platinum accumulation, glutathione level depletion and mitochondrial membrane potential dissipation. These events were accompanied with poly (ADP-ribosyl) polymerase cleavage, stimulation of caspase-3 activity, upregulation of p53, FasL and Gadd45 $\alpha$, cyclin BI downregulation and an increase in mitogen-activated protein kinases JNK, ERK and p38 phosphorylation as well as PI3K level alterations. The presented results might have implications for developing new strategies aimed at therapeutic benefit of natural or synthetic ITCs in cooperation with various anticancer drugs.

British Journal of Cancer (2006) 95, I348- 1353. doi:I0.1038/sj.bjc.6603434 www.bjcancer.com

Published online 24 October 2006

(C) 2006 Cancer Research UK

Keywords: cisplatin; E-4IB isothiocyanate; apoptosis; cell cycle

Chemotherapy constitutes an essential approach of ovarian cancer treatment. Combined sensitiser/inducer concept in specific sequence, aimed at bringing tumour cell populations into a state where they are most susceptible to cytotoxic effects of chemotherapeutic agents, may be a novel strategy to enhance the efficacy of anticancer therapy in a variety of human cancers (Sampath and Plunkett, 2001; Schuchmann et al, 2006).

Cisplatin, one of the most potent antitumour agents with clinical activity against a variety of solid tumours, had changed the course of therapeutic management of these tumours (Zamble et al, 1998; Cohen and Lippard, 2001). Cytotoxicity of cisplatin is mediated by formation of DNA adducts as the key structures activating several signal transduction pathways including MAPKs resulting in activation of apoptosis (Siddik, 2003; Wang and Lippard, 2005). Intensive search for new compounds that could interfere with these pathways can help to increase platinum efficacy (Abou El Hassan et al, 2004; Wernyj and Morin, 2004; Rothermundt et al, 2006).

Naturally occurring isothiocyanates (ITCs) have been known to be effective chemopreventive agents (Steinmetz and Potter, 1991) and to exhibit a protective effect against cancers in a variety of target organs (Morse et al, 1993; Hecht, 1995). Isothiocyanates perturb several steps in the carcinogenic process by inhibiting cell growth due to cell cycle arrest and removing premalignant and malignant cells through the activation of apoptosis (GametPayrastre et al, 2000; Miyoshi et al, 2004; Pullar et al, 2004).

*Correspondence: Dr J Sedlak; E-mail: exonsedl@savba.sk Received 3 August 2006; revised 22 September 2006; accepted 25 September 2006; published online 24 October 2006
In the previous study (Bodo et al, 2006), we introduced a new synthetic ITC-derivative, ethyl 4-isothiocyanatobutanoate (E-4IB), as an efficient modulator of cell cycle and apoptosis. In search for novel strategies to sensitise tumour cells, the objective of this study was to describe further activities of E-4IB to render cisplatininduced apoptosis in human ovarian tumour cell line A2780. We indicated that this ITC-derivative enhanced intracellular platinum accumulation and conferred the cells a state of increased responsiveness to cisplatin-induced apoptosis associated with alterations in cell cycle protein regulation, glutathione (GSH) levels, caspase- 3 activation, mitochondrial potential and signalling pathways including MAPKs family members.

\section{MATERIALS AND METHODS}

\section{Reagents}

E-4IB was synthesised as described (Floch et al, 1997). Dimethyl sulphoxide (DMSO), RNase A, monochlorobimane (MCB) and propidium iodide (PI) were obtained from Sigma Chemical Co. (St Louis, MO, USA). Cisplatin was acquired from LACHEMA (Brno, Czech Republic). Rabbit polyclonal antibodies against ERK1/2, phospho-ERK1/2, JNK1/2, p38, FasL, actin, PARP, p21, p53, Gadd $45 \alpha$, cyclin B1 and horseradish peroxidase-conjugated antirabbit antibody were obtained from Santa Cruz Biotechnology (Santa Cruz, CA, USA). Rabbit polyclonal anti-ACTIVE JNK- and anti-ACTIVE p38 antibodies were purchased from Promega (Medison, WI, USA). Cationic JC-1 dye was a product of Molecular Probes (Eugene, OR, USA). Caspase substrate (Ac-DEVD) and 
caspase inhibitor (Z-DEVD) were gained from Alexis (Lausen, Switzerland).

\section{Cell culture, drug treatments, clonogenic assay and apoptosis}

Human ovarian carcinoma cells A2780 were routinely cultured in RPMI 1640 medium supplemented with $10 \%$ heat-inactivated FCS, $2 \mathrm{mM}$ L-glutamine, $100 \mu \mathrm{g} \mathrm{ml}^{-1}$ penicillin and $50 \mu \mathrm{g} \mathrm{ml}^{-1}$ strepto-

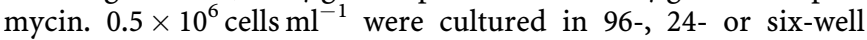
plates (Greiner, Germany). Cells were incubated with E-4IB or cisplatin at indicated concentrations and time determined by MTT assay (Bodo et al, 2005). In combination, we used sequential treatments with E-4IB followed by cisplatin, when E4IB was added $3 \mathrm{~h}$ before cisplatin. Clonogenic growth after treatments for 7 days was assessed by Giemsa-Romanowski staining and measured using Image $1.33 \mathrm{u}$ software (National Institutes of Health, USA). Apoptosis was assessed by flow cytometric analysis of PI-stained nuclei as previously described (Jakubikova et al, 2005).

\section{Measurements of platinum accumulation}

Flameless atomic absorption spectrophotometry (FAAS) was used to analyse platinum levels in tested cells. Cultures were digested in nitric acid followed by $\mathrm{H}_{2} \mathrm{O}_{2}$ and $\mathrm{HCl}$ addition. Flameless atomic absorption spectrophotometry measurements were performed with a Varian AA240Z Zeeman atomic absorption spectrometer equipped with a GTA 120 graphite tube atomizer (Crul et al, 2001; Pluim et al, 2004).

\section{GSH assay}

Cells were seeded in 96-well microplates (black wells with transparent bottom) at a density of $5 \times 10^{3}$ well $^{-1}$ and allowed to adhere in the growth medium to $50-60 \%$ confluence before being exposed to the tested drugs and buthionine-sulphoximine (BSO), respectively, for 3,6 or $27 \mathrm{~h}$ in quadruplicates. After incubation with $\mathrm{MCB}(40 \mu \mathrm{M})$ in the dark, at room temperature for $20 \mathrm{~min}$ and several washings, samples were measured at $390 / 520 \mathrm{~nm}$ (excitation/emission) using the POLARstar fluorimeter (BMG Labtech GmbH, Germany) (Kamencic et al, 2000).

\section{Caspase- 3 activity and mitochondrial potential determination}

Measurements of caspase- 3 activity were performed with the use of fluorescence technique as described (Moriya et al, 2000). Briefly, $3 \times 10^{6}$ washed cells were lysed in a buffer $(\mathrm{pH} 7.5)$ containing $50 \mathrm{~mm}$ TRIS, $1 \mathrm{~mm}$ EDTA, $10 \mathrm{~mm}$ EGTA, $0.5 \%$ Triton X-100 and $1 \mathrm{~mm}$ DTT for $10 \mathrm{~min}$ and samples were centrifuged at $10.000 \mathrm{~g}$ for $10 \mathrm{~min}$. Cleared lysates (10 $\mu \mathrm{g}$ of protein) containing $50 \mu \mathrm{M}$ of substrate were incubated at $37^{\circ} \mathrm{C}$ for $1 \mathrm{~h}$. An amount of released AFC (7-amino-4-trifluoromethyl coumarin) was measured with the POLARstar fluorimeter using excitation at $390 \mathrm{~nm}$ and emission at $520 \mathrm{~nm}$.

Mitochondrial membrane potential $\left(\Psi_{\mathrm{m}}\right)$ was assessed by JC-1 dye measurement of red/green fluorescence ratio as described (Jakubikova et al, 2005). Briefly, cells were washed twice with PBS and incubated with $400 \mu \mathrm{l}$ of PBS/ $0.2 \%$ BSA containing $4 \mu \mathrm{M}$ of JC1 , at $37^{\circ} \mathrm{C}$ for $30 \mathrm{~min}$. Fluorescence was measured by Coulter Epics Altra flow cytometer. Data were analysed by the WinMDI version 2.8 software (J Trotter, Scripps Research Institute, La Jolla, CA, USA).

\section{Western blot analysis}

To examine effects of E-4IB and cisplatin on membrane protein expression, A2780 cells were harvested at indicated times, lysed in a buffer as described (Bodo et al, 2006). For each lane $50 \mu \mathrm{g}$ of protein were loaded. Blots were incubated with the indicated antibodies and horseradish peroxidase-conjugated anti-rabbit secondary antibody (1:3000 diluted). All primary antibodies were used at final concentration $1 \mu \mathrm{g} \mathrm{ml}^{-1}$. Enhanced chemiluminescence (ECL, Amersham Arlington Heights, IL, USA) was used for detection. Expression of actin was used as a control for equal gel loading.

\section{Statistical analysis}

Statistical significance was analysed by Analysis of variance (ANOVA) and post hoc (Tukey) tests.

\section{RESULTS}

\section{Cell sensitisation and growth inhibition}

In the recent paper (Bodo et al, 2005), we referred relatively low cytotoxic activity of synthetic ITC E-4IB in human ovarian A2780 cells and tested it in combination with conventional cytotoxic drug cisplatin. To study experimental conditions, we fixed treatment dose- and time-schedule $(2.5,5 \mu \mathrm{M}$ E-4IB; $5,10 \mu \mathrm{m}$ cisplatin, for 6 or $27 \mathrm{~h}$ ) and found that pretreatment of cisplatin with E-4IB (E$4 \mathrm{IB} /$ cisplatin) induced apoptosis in a dose- and time-dependent manner. We also observed that sequential treatment with E-4IB followed by cisplatin yielded more apoptotic cells than cotreatment with both compounds. In the present study we showed that E-4IB cooperated with cisplatin to inhibit clonogenic tumour cell growth (Table 1). To study E-4IB and cisplatin effects, experiments revealed that cellular accumulation of platinum in combination with E-4IB (E-4IB/cisplatin) is more than three-fold higher $\left(9.28 \pm 0.69 \mathrm{ng} \mathrm{Pt} / 10^{6}\right.$ cells) than that observed with a single cisplatin $\left(2.97 \pm 0.32 \mathrm{ng} \mathrm{Pt} / 10^{6}\right.$ cells) (Table 2$)$.

Table I Effect of E-4IB on cisplatin-induced clonogenic survival

\begin{tabular}{|c|c|c|}
\hline \multicolumn{2}{|c|}{ Concentration $(\mu \mathrm{M})$} & \multirow{2}{*}{$\begin{array}{c}\text { Relative averag } \\
\text { Count }\end{array}$} \\
\hline E-4IB & Cisplatin & \\
\hline - & - & $1.00 \pm 0.00$ \\
\hline 0.5 & - & $0.91 \pm 0.06$ \\
\hline I & - & $0.79 \pm 0.09$ \\
\hline - & 0.1 & $0.74 \pm 0.05 *$ \\
\hline 0.5 & 0.1 & $0.64 \pm 0.11$ \\
\hline I & 0.1 & $0.40 \pm 0.02^{\#}$ \\
\hline - & 0.25 & $0.43 \pm 0.08 * *$ \\
\hline 0.5 & 0.25 & $0.32 \pm 0.02$ \\
\hline I & 0.25 & $0.10 \pm 0.09^{\#}$ \\
\hline
\end{tabular}

$\mathrm{E}-4 \mathrm{IB}=$ ethyl 4 -isothiocyanatobutanoate. $\mathrm{A} 2780$ cells were treated with 0.1 or $0.25 \mu \mathrm{M}$ cisplatin in the presence or absence of 0.5 or I $\mu \mathrm{M} \mathrm{E}-4 \mathrm{IB}$. Clonogenic survival was assessed by Giemsa-Romanowski staining after 7 days and colony numbers per well of a six-well plate are indicated. Statistical significant differences from the controls, $* P<0.05$, $* * P<0.01$, and from the corresponding cisplatin-treated samples, ${ }^{\#} P<0.05$.

Table 2 Effect of E-4IB on platinum intracellular accumulation

\begin{tabular}{|c|c|c|c|c|}
\hline Samples & Control & E-4IB & Cisplatin & E-4IB+cisplatin \\
\hline ng Pt/ $10^{6}$ cells & $0.29 \pm 0.04$ & $0.34 \pm 0.13$ & $2.97 \pm 0.32 * *$ & $9.28 \pm 0.69^{\# \#}$ \\
\hline
\end{tabular}




\section{GSH level alterations}

In ovarian cancer cells, increased GSH levels have been correlated directly with the drug resistance (Okuno et al, 2003). We investigated therefore the capacity of A2780 ovarian cancer cells, treated cells with E-4IB and/or cisplatin, to regulate GSH. Experiments aimed at the testing of a single drug or sequential treatments with E-4IB followed by cisplatin showed GSH decrease in a dose- and time-dependent manner. Glutathione inhibition by BSO was utilised as control (Figure 1A and B).

\section{Caspase-3 activity and mitochondrial potential $\Psi_{\mathrm{m}}$}

Fluorescence substrate (Ac-DEVD-AFC) detection test was used to see whether sensitisation by E-4IB followed by cisplatin involves caspase- 3 activation. We found that caspase- 3 is involved in a single cisplatin treatment and its activity is increased at E-4IB/ cisplatin combination in a dose- and time-dependent manner (Figure 2A). In addition, caspase-3 inhibition Z-DEVD technique was used for the quantification of $\Delta \Psi_{\mathrm{m}}$. Incubation of cells in the presence of E-4IB/cisplatin caused a significant reduction in $\Psi_{\mathrm{m}}$ in a dose-dependent manner and this was inhibited by Z-DEVD (Figure 2B). Finally, we analysed the involvement of caspase- 3 in E-4IB sensitisation using Z-DEVD inhibitor. As observed by detection of sub- $G_{1}$ population measured by flow cytometry,
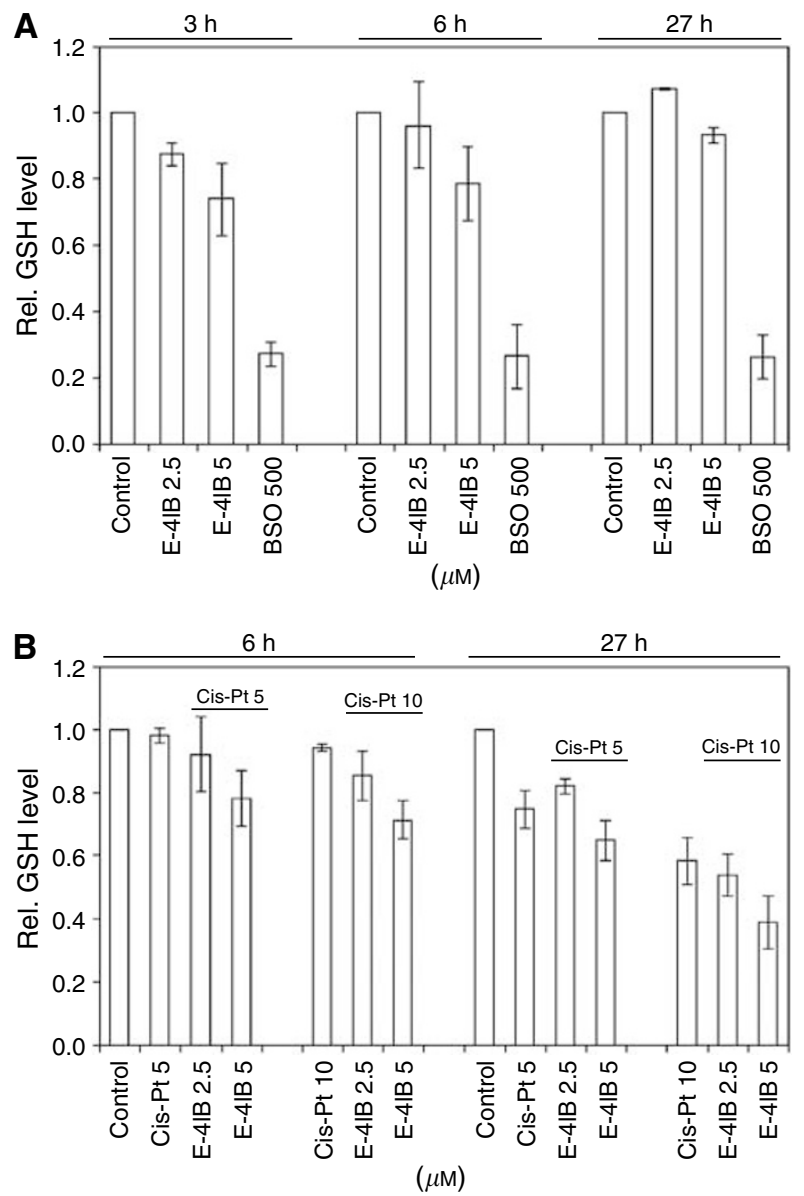

Figure I (A) Modulation of GSH levels after E-4IB treatment. A2780 cells were exposed to 2.5 and $5 \mu \mathrm{M}$ E-4IB for 3,6 and $27 \mathrm{~h}$. BSO (500 $\mu \mathrm{M})$ was used as a control for GSH inhibition. (B) Cisplatin or E-4IB/cisplatininduced alterations in GSH levels. A2780 cells were exposed to E-4IB (2.5 or $5 \mu \mathrm{M})$ for $3 \mathrm{~h}$ followed by cisplatin $(5$ or $10 \mu \mathrm{M})$ for 3 or $24 \mathrm{~h}$. The results shown are representative of at least three independent experiments.
Z-DEVD significantly reduced E-4IB/cisplatin-induced apoptosis (Figure 2C).

\section{Modulation of apoptosis regulatory molecules}

To gain further inside into the molecular mechanism(s) of apoptosis regulation upon treatment with the studied drugs by
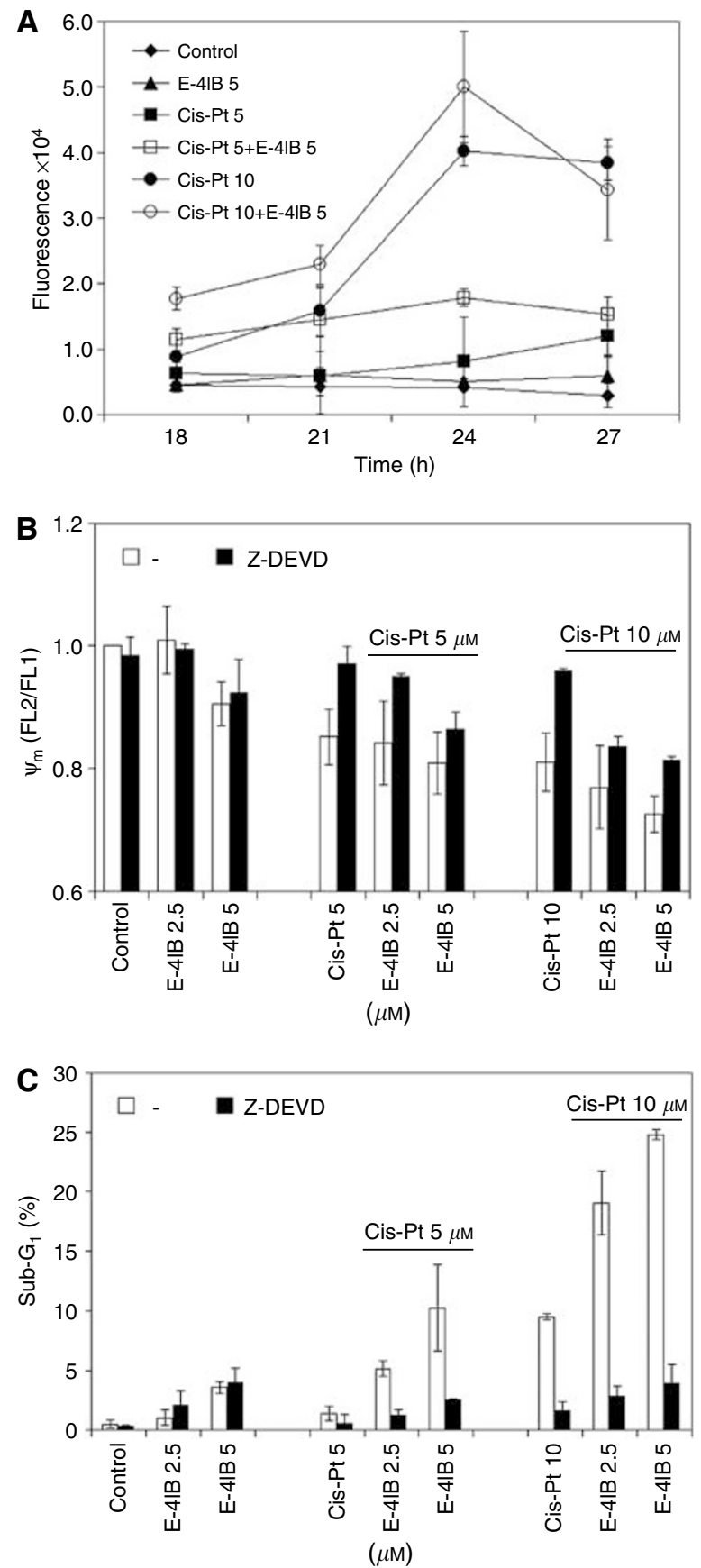

Figure 2 (A) Activation of caspase-3 after E-4IB and/or cisplatin treatment in A2780 cells. The cells were exposed to E-4IB $(5 \mu \mathrm{M})$ for $3 \mathrm{~h}$ followed by cisplatin ( 5 or $10 \mu \mathrm{M}$ ). Caspase- 3 activity was measured using fluorogenic substrate Ac-DEVD-AFC. (B) Modulation of $\Psi_{\mathrm{m}}$. Caspase-3 inhibitor (Z-DEVD) was added to culture medium for I $\mathrm{h}$ before the exposure of the cells to 2.5 or $5 \mu \mathrm{M} \mathrm{E}-4 \mathrm{IB}$ for $3 \mathrm{~h}$ followed by cisplatin ( 5 or $10 \mu \mathrm{M}$, for 3 or $24 \mathrm{~h}$ ). (C) Effect of Z-DEVD on the sub-G, population in the cells treated by E-4IB and/or cisplatin. Sub-GI was calculated by flow cytometry. The results are representative of at least three independent experiments. 
A

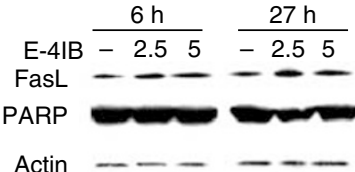

B

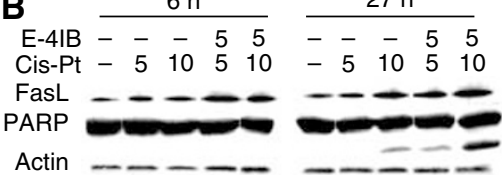

Figure 3 Western blots of apoptosis-related proteins FasL and PARP. A2780 cells were exposed to E-4IB (A) or cisplatin or E-4IB/cisplatin (B). Experimental conditions were used as shown in Figure I. Western blot analysis was performed with total cell extracts. Fifty micrograms of cell lysate was applied for FasL or PARP expression. Actin was utilised for equal protein loading.

A

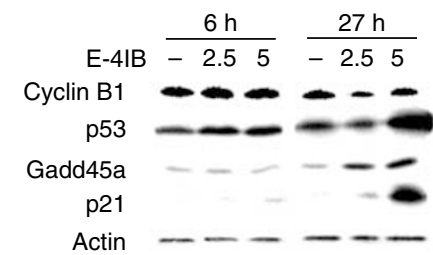

B

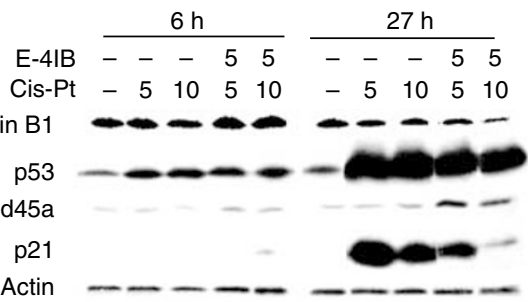

Figure 4 Western blot analysis of A2780 cell protein extracts after E-4IB (A), or cisplatin or E-4IB/cisplatin treatments (B). Cyclin BI, p53, p2I and Gadd $45 \alpha$ protein levels were evaluated. Experimental conditions were used as shown in Figure 1

Western blot analysis, we inspected several key molecules associated with these events. Treatment with a single E-4IB resulted in upregulation of FasL, but no PARP cleavage appeared (Figure 3A). However, E-4IB significantly enhanced the ability of cisplatin to induce PARP cleavage. Additionally, E-4IB/cisplatin treatments led to the enhancement of FasL levels which culminated at $5 \mu \mathrm{M} \mathrm{E}-4 \mathrm{IB} / 10 \mu \mathrm{M}$ cisplatin concentrations (Figure $3 \mathrm{~B}$ ).

\section{Modulation of cell cycle regulation proteins}

To study cell cycle protein alterations, we examined the levels of cell cycle-responsive molecules such as cyclin B1, p53, p21 and Gadd $45 \alpha$ (growth arrest- and DNA damage-inducible protein). Ovarian cells were exposed to E-4IB (Figure 4A) and/or cisplatin (Figure 4B) and visualised by Western blotting. P53, p21 and Gadd $45 \alpha$ levels were enhanced by a single E-4IB treatment in a time- and dose-dependent manner. On the contrary, cyclin B1 levels significantly dropped after E-4IB or E-4IB/cisplatin treatments. Interestingly, after prolonged time $(27 \mathrm{~h})$, abundant amounts of p53 after cisplatin or E-4IB/ciplatin treatments were determined. However, p21 levels culminated at the concentration of $5 \mu \mathrm{M}$ cisplatin and then continuously decreased due to increased cisplatin or E-4IB/cisplatin concentrations. Surprisingly, single cisplatin treatments exerted no alterations in Gadd $45 \alpha$ levels, but
A
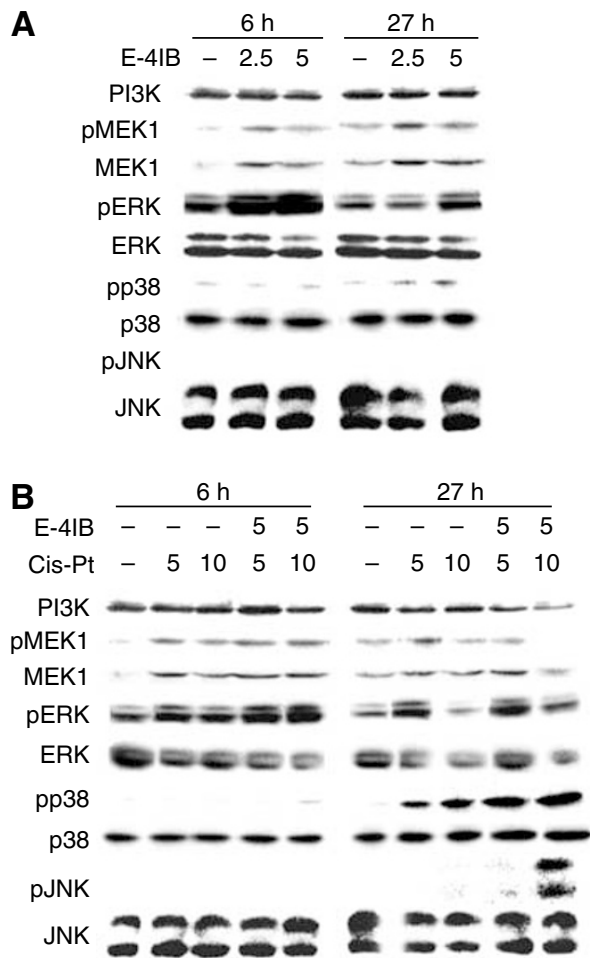

Figure 5 Western blot analyses of E-4IB $(\mathbf{A})$ or cisplatin or E-4IB/ cisplatin (B). ERKI/2, pERKI/2, JNKI/2, pJNKI/2, p38, pp38, MEKI, pMEKI and PI3K protein levels were determined. Cells were treated as shown in Figure 1.

these remained at similar levels as observed with a single E-4IB (Figure 4A and B).

\section{Protein kinases alterations}

Alterations in the activities of the MAPKs and PI3K levels are generally supposed to be associated with the control of cell proliferation, differentiation and death (Wada and Penninger, 2004). In this context, after extracellular stimuli with E-4IB and/or cisplatin, we assessed MAPKs activities to be linked with phosphorylation and also measured PI3K alterations. Single E4IB administration (Figure 5A) exerted no influence on constitutive ERK1/2 levels. However, upregulation of both constitutive and phosphorylated MEK1, in a dose-dependent manner, was observed and this correlated with an enhancement of ERK1/2 phosphorylation. Interestingly, no substantial alterations in constitutive JNK1/2 and p38 MAPK were determined, whereas phosphorylated p38 MAPK form rose. Contrariwise, $27 \mathrm{~h} \mathrm{E}-4 \mathrm{IB} /$ cisplatin treatment was linked to an enhanced phosphorylation of both JNK and p38 MAPK. Conversely, MEK1, pMEK1, ERK1/2 and PI3K (phosphatidylinositol 3-kinase) contents were lowered (Figure 5B).

\section{DISCUSSION}

The major mode of cisplatin effect is mediated by interaction with DNA to form DNA adducts and activation several signal transduction pathways that culminate in a variety of tumour cell lines in the cell growth arrest and apoptosis. In chemotherapy cisplatin was utilised to cooperate with several anticancer compounds to enhance efficacy of its antitumour activity generally resulting in apoptosis (Reed, 1998; Roberts et al, 2005; SiegelLakhai et al, 2005). 
In search for strategy to study several natural and synthetic compounds in chemotherapy we (Bodo et al, 2005) and others (Fimognari et al, 2006) recently referred activities of ITCs as 'sensitizers' followed by conventional chemotherapeutic compounds as 'inducers', to trigger inhibition of proliferation and their synergy to stimulate apoptosis in cancer cells. We further showed that the cytostatic activity of E-4IB was more pronounced than its cytotoxic activity at equimolar concentrations. In the present study, using the same experimental system, we confirmed this synergy by clonogenic assay and investigated for the first time signalling pathways due to their cooperative effect. We determined that E-4B/cisplatin-induced apoptosis correlated with enhanced intracellular platinum accumulation. These events were associated with GSH depletion, downregulation of cyclin B1, mitochondrial potential dissipation, PARP cleavage, p53-, Gadd $45 \alpha$ - and p21upregulation, attesting to the specific effect of E-4IB sensitisation for cisplatin-induced cell cycle alterations and apoptosis.

The mechanisms of cellular uptake and efflux of cisplatin are still not fully understood. However, it was documented that intracellular GSH and exporter proteins have an important role in those processes, presumably by drug inactivation and drug efflux promotion (Mistry et al, 1993; Wang and Lippard, 2005). In the present study we found reduction of intracellular GSH in a dosedependent manner after E-4IB treatments. Thus, observed increase of platinum intracellular accumulation stimulated by E-4IB pretreatments could be explained by a decrease of GSH availability to form cisplatin conjugates and thereby subsequent reduction of cellular efflux of the drug.

It has been shown that activation of JNK leads to targeting of the activator protein-1 (AP-1) transcription factor complex binding sites in the promoters of multiple target genes such as FasL, an element of death receptor-dependent apoptotic signalling cascade (Le Niculescu et al, 1999). In this context, combination E-4IB and cisplatin in our experimental conditions led to marked enhancement in FasL levels. Thus, we also assume that FasL may play an important role in initiation of E-4IB/cisplatin-induced apoptosis.

The molecular mechanisms for cisplatin-induced apoptosis involved caspase-3 activation (Kolfschoten et al, 2002). To see an importance of caspase-3, we inspected the activity of the enzyme and demonstrated a time- and dose-dependent activation of caspase- 3 caused by single drug treatments or in combination. Flow cytometric analysis aimed at the regulation of mitochondrial potential and an appearance of sub-G1 portion of apoptotic cells confirmed an essential role of this enzyme in E-4IB/cisplatininduced apoptosis.

Our results further showed marked increase in p53 levels after cisplatin treatment, which, surprisingly, were not affected by E-4IB sensitisation. These events were after E-4IB/cisplatin treatments associated with moderate increase in Gadd $45 \alpha$ protein levels. This may suggest that E-4IB, concomitantly with Gadd $45 \alpha$ (growth arrest- and DNA damage-inducible protein), might contribute to the transcription activation of p53. In fact, in response to genotoxic stimuli, Gadd $45 \alpha$ was shown to be increased and participated in nucleotide excision repair thereby it sensitised different tumours to undergo apoptosis (Sheikh et al, 2000). P53 and cdk inhibitor p21 have also been determined to maintain $\mathrm{G}_{2}$ arrest following DNA damage (Taylor and Stark, 2001). In addition, some experimental data show that p21 blocks cell cycle progression through its negative activity on various cyclindependent kinases and apoptosis through inhibition of caspases activation (Viallard et al, 2001). These events involve an initial inhibition of cyclin B1/Cdc2 activity by $\mathrm{p} 21$ and a subsequent reduction of cyclin B1 (Charrier-Savournin et al, 2004). In relation to the reduction of cyclin $\mathrm{B} 1$ observed in our experiments we assume that the diminution of p21 observed after E-4IB/ cisplatin combination treatments facilitate the cells to trigger apoptosis.

Three MAPK members (JNK, ERK and p38) participate in integrating extracellular signals to regulate cell proliferation, differentiation, cell survival and apoptosis (Dent and Grant, 2001). The kinases were activated following exposure of tumour cells to cisplatin, when ERK activation might be critical for cisplatin-induced apoptosis (Persons et al, 2000; Yeh et al, 2002). Furthermore, the duration of JNK- and p38 MAPK activation was demonstrated as an early key determinant of cisplatin-induced apoptosis (Sanchez-Perez et al, 1998; Benhar et al, 2001; Mansouri et al, 2003; Kusama et al, 2006). In accordance with these results we presented here sustained activation/phosphorylation of p38 MAPK and this was associated with E-4IB/cisplatin-induced apoptosis.

Phosphatidylinositol 3-kinase is believed to be important cell survival factor in human ovarian cancer cells (Asselin et al, 2001). PI3K/AKT pathway facilitates $G_{1}$ to $S$ phase progression and plays a major role in protecting of cells from apoptosis by inhibiting Bad and thus cytochrome $c$ release, inactivating caspase- 3 and targeting p53 for its destruction (Kennedy et al, 1997). In our experimental system we found continuous downregulation of PI3-kinase and, in concordance with others, we assume that these events facilitate cell cycle arrest and apoptosis as a consequence of E-4IB/cisplatin treatment.

The presented results indicate the potential of E-4IB for anticancer therapy may largely reside in its ability to sensitise tumour cells to overcome cisplatin resistance and to induce apoptosis. Thereby, our studies showed potential application of E4IB as sensitiser for cytotoxic therapies in ovarian cancer cells. Finally, in terms of clinical perspective, the combined sensitiser (E4IB)/inducer (cisplatin) strategy may be a novel approach to enhance the efficacy of anticancer therapy in some human cancers.

\section{ACKNOWLEDGEMENTS}

We gratefully acknowledge expert technical assistance by Ms Jana Chovancova. This work was supported in part by Slovak Governmental Research and Development sub-program Foodquality and safety No. 2003SP270280E010280E01, Slovak Grant Agency VEGA (No. 2/5042/25), European Social Fund (project code 13120200038), National Program 'Use of Cancer Genomics to Improve the Human Population Health', project 2003 SP $510280800 / 0280801$

\section{REFERENCES}

Abou El Hassan MA, Mastenbroek DC, Gerritsen WR, Giaccone G, Kruyt FA (2004) Overexpression of Bcl2 abrogates chemo- and radiotherapyinduced sensitisation of NCI-H460 non-small-cell lung cancer cells to adenovirus-mediated expression of full-length TRAIL. $\mathrm{Br}$ J Cancer 91: $171-177$

Asselin E, Mills GB, Tsang BK (2001) XIAP regulates Akt activity and caspase-3-dependent cleavage during cisplatin-induced apoptosis in human ovarian epithelial cancer cells. Cancer Res 61: 1862-1868
Benhar M, Dalyot I, Engelberg D, Levitzki A (2001) Enhanced ROS production in oncogenically transformed cells potentiates c-Jun $\mathrm{N}$ terminal kinase and p38 mitogen-activated protein kinase activation and sensitization to genotoxic stress. Mol Cell Biol 21: 6913-6926

Bodo J, Chovancova J, Hunakova L, Sedlak J (2005) Enhanced sensitivity of human ovarian carcinoma cell lines A2780 and A2780/CP to the combination of cisplatin and synthetic isothiocyanate ethyl 4-isothiocyanatobutanoate. Neoplasma 52: 510-516 
Bodo J, Jakubikova J, Chalupa I, Bartosova Z, Horakova K, Floch L, Sedlak J (2006) Apoptotic effect of ethyl-4-isothiocyanatobutanoate is associated with DNA damage, proteasomal activity and induction of p53 and p21(cip1/waf1). Apoptosis 11: 1299-1310

Charrier-Savournin FB, Chateau MT, Gire V, Sedivy J, Piette J, Dulic V (2004) p21-mediated nuclear retention of cyclin B1-Cdk1 in response to genotoxic stress. Mol Biol Cell 15: 3965-3976

Cohen SM, Lippard SJ (2001) Cisplatin: from DNA damage to cancer chemotherapy. Prog Nucleic Acid Res Mol Biol 67: 93-130

Crul M, van den Bongard HJ, Tibben MM, van Tellingen O, Sava G, Schellens JH, Beijnen JH (2001) Validated method for the determination of the novel organo-ruthenium anticancer drug NAMI-A in human biological fluids by Zeeman atomic absorption spectrometry. Fresenius $J$ Anal Chem 369: $442-445$

Dent P, Grant S (2001) Pharmacologic interruption of the mitogenactivated extracellular-regulated kinase/mitogen-activated protein kinase signal transduction pathway: potential role in promoting cytotoxic drug action. Clin Cancer Res 7: 775-783

Fimognari C, Nusse M, Lenzi M, Sciuscio D, Cantelli-Forti G, Hrelia P (2006) Sulforaphane increases the efficacy of doxorubicin in mouse fibroblasts characterized by p53 mutations. Mutat Res, in press

Floch L, Kuban J, Gogova A, Jakubik T, Pronayova N (1997) Synthesis of ethyl 4-isothiocyanatobutanoate derivatives. Chem Pap-Chem Zvesti 51: $416-420$

Gamet-Payrastre L, Li P, Lumeau S, Cassar G, Dupont MA, Chevolleau S, Gasc N, Tulliez J, Terce F (2000) Sulforaphane, a naturally occurring isothiocyanate, induces cell cycle arrest and apoptosis in HT29 human colon cancer cells. Cancer Res 60: 1426-1433

Hecht SS (1995) Chemoprevention by isothiocyanates. J Cell Biochem Suppl 22: $195-209$

Jakubikova J, Bao Y, Sedlak J (2005) Isothiocyanates induce cell cycle arrest, apoptosis and mitochondrial potential depolarization in HL-60 and multidrug-resistant cell lines. Anticancer Res 25: 3375-3386

Kamencic H, Lyon A, Paterson PG, Juurlink BH (2000) Monochlorobimane fluorometric method to measure tissue glutathione. Anal Biochem 286: $35-37$

Kennedy SG, Wagner AJ, Conzen SD, Jordan J, Bellacosa A, Tsichlis PN, Hay N (1997) The PI 3-kinase/Akt signalling pathway delivers an antiapoptotic signal. Genes Dev 11: 701 - 713

Kolfschoten GM, Hulscher TM, Schrier SM, van Houten VM, Pinedo HM, Boven E (2002) Time-dependent changes in factors involved in the apoptotic process in human ovarian cancer cells as a response to cisplatin. Gynecol Oncol 84: 404-412

Kusama T, Mukai M, Tatsuta M, Nakamura H, Inoue M (2006) Inhibition of transendothelial migration and invasion of human breast cancer cells by preventing geranylgeranylation of Rho. Int J Oncol 29: 217-223

Le Niculescu H, Bonfoco E, Kasuya Y, Claret FX, Green DR, Karin M (1999) Withdrawal of survival factors results in activation of the JNK pathway in neuronal cells leading to Fas ligand induction and cell death. Mol Cell Biol 19: $751-763$

Mansouri A, Ridgway LD, Korapati AL, Zhang Q, Tian L, Wang Y, Siddik ZH, Mills GB, Claret FX (2003) Sustained activation of JNK/p38 MAPK pathways in response to cisplatin leads to Fas ligand induction and cell death in ovarian carcinoma cells. J Biol Chem 278: 19245 - 19256

Mistry P, Loh SY, Kelland LR, Harrap KR (1993) Effect of buthionine sulfoximine on PtII and PtIV drug accumulation and the formation of glutathione conjugates in human ovarian-carcinoma cell lines. Int $J$ Cancer 55: 848-856

Miyoshi N, Takabayashi S, Osawa T, Nakamura Y (2004) Benzyl isothiocyanate inhibits excessive superoxide generation in inflammatory leukocytes: implication for prevention against inflammation-related carcinogenesis. Carcinogenesis 25: 567-575

Moriya R, Uehara T, Nomura Y (2000) Mechanism of nitric oxideinduced apoptosis in human neuroblastoma SH-SY5Y cells. FEBS Lett 484: $253-260$

Morse MA, Zu H, Galati AJ, Schmidt CJ, Stoner GD (1993) Dose-related inhibition by dietary phenethyl isothiocyanate of esophageal tumorigen- esis and DNA methylation induced by $N$-nitrosomethylbenzylamine in rats. Cancer Lett 72: $103-110$

Okuno S, Sato H, Kuriyama-Matsumura K, Tamba M, Wang H, Sohda S, Hamada H, Yoshikawa H, Kondo T, Bannai S (2003) Role of cystine transport in intracellular glutathione level and cisplatin resistance in human ovarian cancer cell lines. Br J Cancer 88: 951 - 956

Persons DL, Yazlovitskaya EM, Pelling JC (2000) Effect of extracellular signal-regulated kinase on p53 accumulation in response to cisplatin. J Biol Chem 275: $35778-35785$

Pluim D, van Waardenburg RC, Beijnen JH, Schellens JH (2004) Cytotoxicity of the organic ruthenium anticancer drug Nami-A is correlated with DNA binding in four different human tumour cell lines. Cancer Chemother Pharmacol 54: 71-78

Pullar JM, Thomson SJ, King MJ, Turnbull CI, Midwinter RG, Hampton MB (2004) The chemopreventive agent phenethyl isothiocyanate sensitizes cells to Fas-mediated apoptosis. Carcinogenesis 25: 765-772

Reed E (1998) Platinum-DNA adduct, nucleotide excision repair and platinum based anti-cancer chemotherapy. Cancer Treat Rev 24: $331-344$

Roberts D, Schick J, Conway S, Biade S, Laub PB, Stevenson JP, Hamilton TC, O'Dwyer PJ, Johnson SW (2005) Identification of genes associated with platinum drug sensitivity and resistance in human ovarian cancer cells. Br J Cancer 92: 1149-1158

Rothermundt C, Hubner R, Ahmad T, Gibbens I, Keyzor C, Habeshaw T, Kaye S, Gore M (2006) Combination chemotherapy with carboplatin, capecitabine and epirubicin (ECarboX) as second- or third-line treatment in patients with relapsed ovarian cancer: a phase I/II trial. Br J Cancer 94: $74-78$

Sampath D, Plunkett W (2001) Design of new anticancer therapies targeting cell cycle checkpoint pathways. Curr Opin Oncol 13: 484-490

Sanchez-Perez I, Murguia JR, Perona R (1998) Cisplatin induces a persistent activation of JNK that is related to cell death. Oncogene 16: $533-540$

Schuchmann M, Schulze-Bergkamen H, Fleischer B, Schattenberg JM, Siebler J, Weinmann A, Teufel A, Worns M, Fischer T, Strand S, Lohse AW, Galle PR (2006) Histone deacetylase inhibition by valproic acid down-regulates c-FLIP/CASH and sensitizes hepatoma cells towards. Oncol Rep 15: $227-230$

Sheikh MS, Hollander MC, Fornance Jr AJ (2000) Role of Gadd45 in apoptosis. Biochem Pharmacol 59: 43-45

Siddik ZH (2003) Cisplatin: mode of cytotoxic action and molecular basis of resistance. Oncogene 22: $7265-7279$

Siegel-Lakhai WS, Crul M, Zhang S, Sparidans RW, Pluim D, Howes A, Solanki B, Beijnen JH, Schellens JH (2005) Phase I and pharmacological study of the farnesyltransferase inhibitor tipifarnib (Zarnestra, R115777) in combination with gemcitabine and cisplatin in patients with advanced solid tumours. Br J Cancer 93: 1222 - 1229

Steinmetz KA, Potter JD (1991) Vegetables, fruit, and cancer. I. Epidemiology. Cancer Causes Control 2: 325 - 357

Taylor WR, Stark GR (2001) Regulation of the G2/M transition by p53. Oncogene 20: $1803-1815$

Viallard JF, Lacombe F, Belloc F, Pellegrin JL, Reiffers J (2001) Molecular mechanisms controlling the cell cycle: fundamental aspects and implications for oncology. Cancer Radiother 5: 109-129

Wada T, Penninger JM (2004) Mitogen-activated protein kinases in apoptosis regulation. Oncogene 23: 2838-2849

Wang D, Lippard SJ (2005) Cellular processing of platinum anticancer drugs. Nat Rev Drug Disc 4: 307-320

Wernyj RP, Morin PJ (2004) Molecular mechanisms of platinum resistance: still searching for the Achilles' heel. Drug Resist Update 7: 227-232

Yeh PY, Chuang SE, Yeh KH, Song YC, Ea CK, Cheng AL (2002) Increase of the resistance of human cervical carcinoma cells to cisplatin by inhibition of the MEK to ERK signalling pathway partly via enhancement of anticancer drug-induced NF kappa B activation. Biochem Pharmacol 63: $1423-1430$

Zamble DB, Jacks T, Lippard SJ (1998) p53-Dependent and -independent responses to cisplatin in mouse testicular teratocarcinoma cells. Proc Natl Acad Sci USA 95: 6163-6168 